\title{
Pre-service Early Childhood Teachers' Attitude Towards Mathematics: A Jamaican Inquiry
}

\author{
Corey Anthony Williamson \\ Shortwood Teachers' College, Kingston, Jamaica
}

\begin{abstract}
The purpose of the study was to evaluate Jamaican early childhood pre-service teachers' attitudes towards mathematics. The study is designed according to the quantitative survey model in the descriptive type. In this study, a modified version of the Fennema-Sherman mathematics attitude scale was used to measure the mathematics attitude of 144 early childhood pre-service teachers in four different categories of the attitude scale (mathematics usefulness, confidence in learning mathematics, mathematics anxiety, and mathematics motivation). The data were collected from participants in the five teachers' colleges that offer the early childhood education program in Jamaica. The findings revealed that Jamaican early childhood pre-service teachers generally have a more positive attitude towards mathematics. A comparison among the different year groups revealed that a significantly greater percentage of the Year two group of participants possessed a more positive mathematics attitude than the other year groups. A significantly higher percentage of the Year three group indicated that they do not want to teach the subject in the future. The findings have implications for the teaching and learning of mathematics in the early childhood education program in Jamaica and, by extension, the teaching and learning of mathematics at the early childhood level of the education system.
\end{abstract}

Keywords: attitude towards teaching mathematics, early childhood pre-service teachers, mathematics attitude scales

\section{Introduction and Literature Review}

In recent years, policy-makers in the education circle have begun to show a significant growing interest in teacher qualifications to improve school quality and student outcomes (Organization for Economic Co-operation and Development [OECD], 2016). In Jamaica, it was not until recent years that the decision was made to have early childhood trainee teachers acquire additional mathematics courses in their training. This came as a result of policy-makers recognizing the need for early childhood teachers to be more knowledgeable in mathematics in order for them to better educate the nation's children at that level of the education system. According to Guerriero (2014), the most crucial indicator of teacher qualification is their pedagogical knowledge. It has become necessary, however, not only to consider teachers' pedagogical content knowledge, but it has also been accepted that teachers' attitudes towards their subject area is an important determinant for the teacher qualification (McLeod, 1992). The aim of this study was to evaluate Jamaican early childhood pre-service teachers' attitudes towards mathematics and mathematics teaching. Teachers' mathematics attitude among the researches on the affective domain, the attitude has perhaps the longest history and the highest

Corey Anthony Williamson, Ph.D. Candidate (University of the West Indies), Mathematics, Research Lecturer, Shortwood Teachers' College, Kingston, Jamaica. 
popularity in mathematics education (Zan, Brown, Evans, \& Hannula, 2006). According to Ma and Kishor (1997), many researchers have shown that students' attitude towards mathematics is one of the most important factors relating to their achievement in the subject. Teachers' attitude towards mathematics and the teaching of mathematics is considered to be very important, because there is a relationship between their practice in the teaching and learning process and their attitude towards the subject (Ernest, 2004). A number of studies have reported that the mental, physical, and social development of children can be quite rapid during their early years of development. As a result, the development during early childhood and primary education period is particularly important for the future of the children. It is for these reasons that Frakes and Kline (2000) made the point that teachers who teach in the early years of schooling have a powerful impact on the mathematics achievement of children. The quality of teaching in mathematics and the nature of teachers' attitudes towards the subject seem to have a direct influence on students' attitude towards the subject and eventually also on their achievement. Yara (2009) confirmed that teachers with positive attitudes towards the subject stimulate favorable attitudes in their students. Earlier, Henderson and Rodriques (2008) regarded the main source of negative students' attitudes towards mathematics as inappropriate teaching practices and teacher attitudes. Ma and Wilkins (2002) put the vital role of teacher attitudes into perspective, by stating that students who believe that teachers have high expectations of them tend to have a more positive attitude towards mathematics. Pre-service teachers' attitudes towards mathematics influence their approach to their own teaching (during training), how they might teach during their first few years as teachers, as well as the nature of the initial teaching and learning culture in the classroom (Amato, 2004). Measuring students' or pre-service teachers' mathematics attitude is not the solution of the problem of underachievement in the subject. In addition to measuring attitudes towards mathematics, the factors that influence attitudes towards mathematics should also be investigated. If the main idea is to change attitude towards mathematics in a positive direction, it is necessary to know the influencing factors on attitude. According to Nicolaidou and Philippou (2003), these manipulative factors is identified under three main groups: factors related to personal characteristics, factors related to the school environment, and the home environmental factors and society. Considering the research literature about the attitude towards mathematics, mentioned above, the purpose of the research was to evaluate Jamaican early childhood pre-service teachers' attitudes towards mathematics. For this purpose, the following research questions are determined:

1. What is the level of pre-service early childhood teachers' overall attitudes toward mathematics?

2. Are there significant differences among the categories of the mathematics attitude for pre-service early childhood teachers'?

3. Are there significant differences in the mathematics attitude among the different year groups of pre-service early childhood teachers?

\section{Study Design}

The present study is a quantitative study using the survey design. The survey design enables the quantitative or numerical description of data in a population by studying a sample selected within the population (Creswell, 2014).

\section{Participants}

The study measured the mathematics attitude of 144 pre-service early childhood teachers from the five 
teacher training colleges in Jamaica that offer the early childhood education program. The 144 pre-service early childhood teachers ages ranged from 17 to 40 years old and accounted for approximately $90 \%$ of all the pre-service teachers from four different year groups (Years one to four).

\section{Instruments, Reliability, and Data Analysis}

The data used in this study were collected using a modified version of the Fennema-Sherman Mathematics Attitude Scale (FSMAS). The original version of the FSMAS (Fennema \& Sherman, 1976) comprises of nine subscales of 12 items each (making 108 items in total). These subscales assess:

(1) attitudes towards success in mathematics;

(2) mathematics as a male domain;

(3) confidence in learning mathematics;

(4) mathematics anxiety;

(5) effectance motivation;

(6) usefulness of mathematics;

(7) mother perception;

(8) father perception;

(9) teacher perception.

On the other hand, the modified version consists of four out of these nine subscales. They are:

(1) confidence in learning mathematics scale;

(2) usefulness of mathematics scale;

(3) mathematics as a male domain scale;

(4) teacher perception scale.

The modified instrument used in this study (see Appendix) consists of 40 statements and was divided into four categories - usefulness of mathematics, confidence in learning mathematics, mathematics anxiety, and mathematics motivation. Each category of the attitude scale consisted of 10 statements. The SPSS software was used to determine the reliability of the instrument. Table 1 shows the reliability measures of the instrument used in the study.

Table 1

Cronbach Alpha Reliability Coefficients for the Mathematics Attitudes Scale

\begin{tabular}{ll}
\hline Categories of Attitude & Coefficients \\
\hline Overall Coefficient (40 items) & 0.90 \\
Mathematics usefulness (10 items) & 0.71 \\
Confidence in learning mathematics (10 items) & 0.74 \\
Mathematics anxiety (10 items) & 0.75 \\
Mathematics motivation (10 items) & 0.82 \\
\hline
\end{tabular}

\section{Results}

The results of this study are presented and discussed based on the research questions.

\section{Results Based on Research Question 1}

The first research question speaks to the overall mathematics attitude of Jamaican pre-service early childhood teachers. Table 2 shows the overall measures of the mathematics attitude for Jamaican pre-service early childhood teachers. The results revealed that $74 \%$ of Jamaican pre-service early childhood teachers have a 
positive to very positive attitude towards mathematics.

Table 2

Overall Mathematics Attitude of Jamaican Pre-service Early Childhood Teachers

\begin{tabular}{lc}
\hline Mathematics attitude measures & Percentage of Jamaican pre-service early childhood teachers (\%) \\
\hline Positive to very positive mathematics attitude & 74 \\
Negative to very negative mathematics attitude & 26 \\
\hline
\end{tabular}

\section{Results Based on Research Question 2}

The second research question speaks to the differences among the categories of pre-service early childhood teachers' attitudes towards mathematics. As was explained earlier, the mathematics attitude scale consisted of four categories of attitude - mathematics usefulness, confidence in learning mathematics, mathematics anxiety, and mathematics motivation. Table 3 shows the measures of attitude for Jamaican pre-service early childhood teachers in each category of the attitude scale. The results in Table 3 revealed that 99.7\% of the pre-service teachers have a positive to very positive attitude towards the usefulness of mathematics. This is significantly higher compared to their attitude to all the other categories. The results for the other three categories are not significantly different from each other, with the percentage of participants having a positive attitude towards each of the category ranging from $60 \%$ to $69 \%$.

Table 3

Mathematics Attitude for Jamaican Pre-service Early Childhood Teachers in Each Category of the Attitude Scale

\begin{tabular}{ll}
\hline Categories of mathematics attitude & Percentage of Jamaican pre-service early childhood teachers with positive attitude (\%) \\
\hline Mathematics usefulness & 99.7 \\
Confidence in learning mathematics & 69 \\
Mathematics anxiety & 60 \\
Mathematics motivation & 65 \\
\hline
\end{tabular}

\section{Results Based on Research Question 3}

The third and final research question addressed the differences in the mathematics attitude among the different year groups of pre-service early childhood teachers. Figure 1 shows the mathematics attitude results each year group of Jamaican pre-service early childhood teachers. The results in Figure 1 speak specifically to those pre-service teachers with a positive attitude towards mathematics. The results show that the Year two group of pre-service teachers has a significantly greater percentage of teachers with a positive attitude towards mathematics compared to the other year groups. The results showed no significant difference among Years one, three, and four groups. 


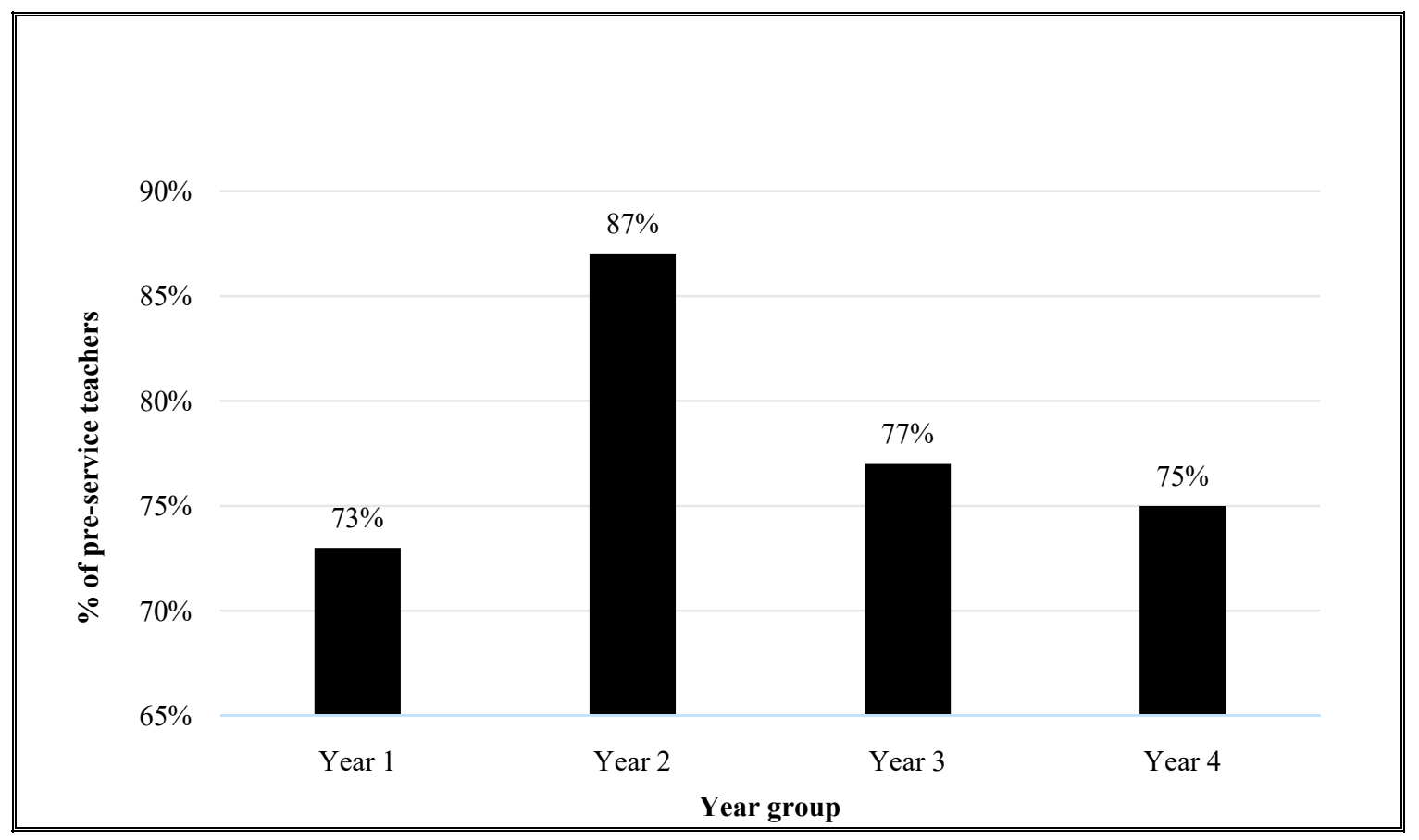

Figure 1. Comparison of Jamaican pre-service early childhood teachers' mathematics attitude by year groups.

\section{Categories of Attitude}

A comparison was also made among the different categories of attitude, based on the responses from the different year groups of pre-service teachers. Table 4 shows the percentage of pre-service early childhood teachers in the different year groups having a positive attitude in the different categories of the attitude scale. A comparison among the different year groups reveals that there is no notable difference among the different year groups in their attitude towards the usefulness of mathematics. The statistics in Table 4 shows that practically all the pre-service teachers in each year group possess a positive attitude towards the usefulness of mathematics.

With regards to the category of confidence in mathematics, the measure of attitude for the Year one group is significantly different compare to the other year groups. A significantly lower percentage of the Year one group of pre-service teachers are confident in learning mathematics compared to the other year groups. There is no significant difference among the Years two, three, and four groups of pre-service teachers in terms of their confidence in learning mathematics.

The mathematics anxiety category shows a similar pattern as that of confidence in mathematics. A significantly higher percentage of the Year one group of pre-service teachers $(53 \%)$ are anxious about mathematics, compared to the other year groups. There is, however, no significant difference among the Years two, three, and four group of pre-service teachers in terms of their anxiety about mathematics.

As to the level of motivation among the different year groups, Table 4 shows a significantly higher percentage of Jamaican pre-service teachers in the Year two group are motivated in learning mathematics. Note is also taken of the fact that a significantly lower percentage of the Year four group (50\%) of pre-service teachers are motivated about mathematics. 
Table 4

Comparison of the Different Categories of Mathematics Attitude Among Different Year Groups of Jamaican Pre-Service Early Childhood Teachers

\begin{tabular}{lllll}
\hline Categories of attitude & Year one (\%) & Year two (\%) & Year three (\%) & Year four (\%) \\
\hline Mathematics usefulness & 100 & 98 & 100 & 100 \\
Confidence in learning mathematics & 57 & 77 & 77 & 75 \\
Mathematics anxiety & 47 & 70 & 66 & 60 \\
Mathematics motivation & 67 & 79 & 65 & 50 \\
\hline
\end{tabular}

\section{Analysis of a Specific Statement Relating to the Teaching of Mathematics}

The study conducted a further analysis with one item on the ability scale relating to the teaching of mathematics. The statement is Item 31 and was measured under the motivation category. The statement is: "I do not want to teach mathematics in the future". The overall results based on all the pre-service teachers' responses to this item showed that $36 \%$ do not want to teach mathematics, $20 \%$ of them are undecided, and $44 \%$ responded that they want to teach the subject in the future. Three percent of the teachers did not respond to the item. In addition to the overall results, the study also analyzed the responses to the statement for each year group of pre-service teachers. Table 5 shows the responses of pre-service teachers for each year group in the study. A comparison among the different year groups shows that a significantly higher percentage of the Year one and Year three groups of pre-service teachers do not want to teach mathematics in the future.

Table 5

Jamaican Pre-service Early Childhood Teachers' Response Result for the Statement: I Do Not Want to Teach Mathematics in the Future

\begin{tabular}{llll}
\hline Year groups & Strongly agree/Agree (\%) & Undecided (\%) & Strong disagree/Disagree (\%) \\
\hline Year one & 45 & 13 & 42 \\
Year two & 28 & 17 & 55 \\
Year three & 42 & 8 & 50 \\
Year four & 30 & 30 & 40 \\
\hline
\end{tabular}

\section{Conclusions}

The following conclusions were made based on the findings of the study:

1. A significantly higher percentage of Jamaican pre-service early childhood teachers have a positive to very positive attitude towards mathematics.

2. A significantly higher percentage of Year two pre-service early childhood teachers have a positive attitude towards mathematics compared to all other year groups.

4. The Year one group of pre-service early childhood teachers are the least confident and the most anxious in terms of the teaching and learning of mathematics.

5. A considerable percentage of Jamaican pre-service early childhood teachers do not want to teach mathematics in the future. 


\section{References}

Amato, S. A. (2004). Improving student teachers' attitudes to mathematics. In M. J. Høines, A. B. Fuglestad, International Group for the Psychology of Mathematics Education, and Bergen University College (Eds.), Proceedings of the 28th Conference of the International Group for the Psychology of Mathematics Education (Vol. 2, pp. 25-32). Bergen: Bergen University College.

Creswell, J. W. (2014). Research design: Qualitative, quantitative and mixed methods approaches (4th ed.). London: Sage Publications Ltd.

Ernest, P. (2004). Images of mathematics, values and gender. In S. Johnston-Wilder and B. Allen (Eds.), Mathematics education: Exploring the culture of learning. London, New York: Routledge.

Fennema, E., \& Sherman, J. (1976). Fennema-Sherman mathematics attitudes scales: Instruments designed to measure attitudes towards learning of mathematics by females and males. Journal for Research in Mathematics Education, 7, 324-326.

Frakes, C., \& Kline, K. (2000). Teaching young mathematicians: The challenges and rewards. Teaching Children Mathematics, 6(6), 376-381.

Guerriero, S. (2014). Pedagogical knowledge and the changing nature of the teaching profession. Paris: OECD Publishing.

Henderson, S., \& Rodrigues, S. (2008). Scottish student primary teachers' levels of mathematics competence and confidence for teaching mathematics: Some implications for national qualifications and initial teacher education. Journal of Teaching: International Research and Pedagogy, 34(2), 93-107. doi:10.1080/02607470801979533

Ma, X., \& Kishor, N. (1997). Assessing the relationship between attitude towards mathematics and achievement in mathematics: A meta-analysis. Journal for Research in Mathematics Education, 28(1), 26-47. Retrieved from https://doi.org/10.2307/749662

Ma, X., \& Wilkins, J. L. M. (2002). The development of science achievement in middle and high school: Individual differences and school effects. Evaluation Review, 26(4), 395-417. Retrieved from https://scholar.vt.edu/access/content/user/wilkins/Public/Ma_Wilkins2002.pdf

McLeod, D. (1992). Research on affect in mathematics education: A reconceptualization. In D. Grows (Ed.), Handbook of research on mathematics teaching and learning (pp. 575-596). New York: McMillan. Retrieved from http://www.peterliljedahl.com/wp-content/uploads/Affect-McLeod.pdf

Nicolaidou, M., \& Philippou, G. (2003). Attitude towards mathematics, self-efficacy and achievement in problem-solving. Proceedings of the 3rd Conference of the European Society for Research in Mathematics Education, 28 February-3 March 2003, Bellaria, Italia.

Organization for Economic Co-operation and Development (OECD). (2016). PISA 2015 assessment and analytical framework: Science, reading, mathematic and financial literacy. Paris: PISA, OECD Publishing. Retrieved from https://doi.org/10.1787/9789264255425-en

Yara, P. O. (2009). Relationships between teachers' attitude and students' academic achievement in Mathematics in some selected senior secondary schools in South West, Nigeria. European Journal of Social Sciences, 11(3), 364-369.

Zan, R., Brown, L., Evans, J., \& Hannula, M. S. (2006). Affect in mathematics education: An introduction. Educational Studies in Mathematics, 63(2), 113-121. Retrieved from https://doi.org/10.1007/s10649-006-9028-2 
Appendix

Mathematics Attitude Scale

Instructions

Place a tick in the appropriate box below

Year: 1
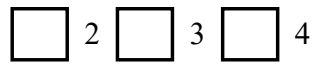

Gender: Male Female

Age Group: 16-25 26-35 $36-45$

This Mathematics Attitude Scale consists of 50 statements about how you feel or think about the teaching and learning of mathematics. If you Strongly Agree with a statement, place a tick under SA; if you just Agree, place a tick under A; if you are Undecided, place a tick under U; if you Disagree, place a tick under D; if you Strongly Disagree, place a tick under SD. Do not write your name.

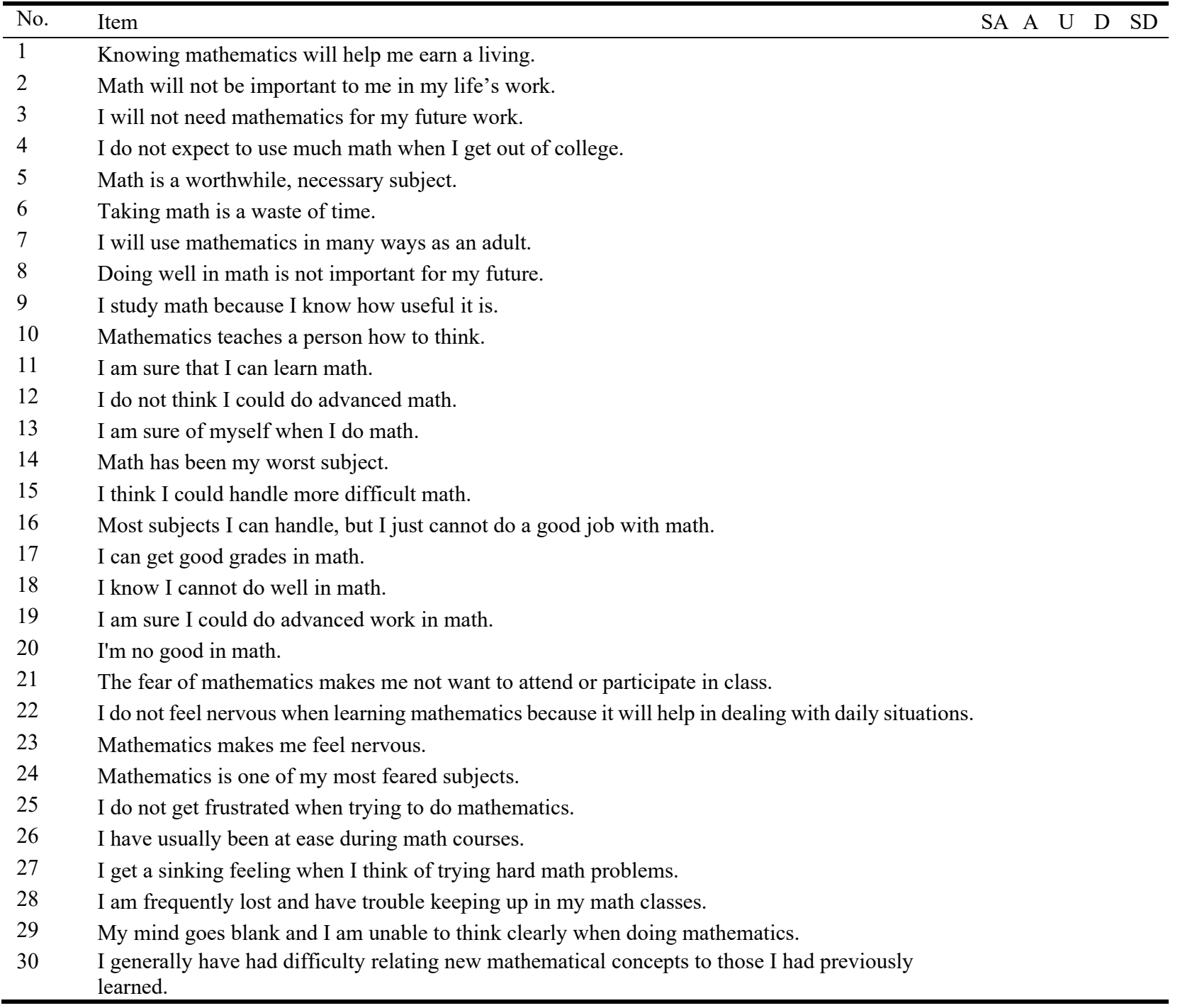


31 I do not want to teach mathematics in the future.

32 It would not bother me at all to take more math courses.

33 I look forward to teaching mathematics in the future.

34 When I had trouble with a concept I usually gave up and stopped trying.

35 I enjoy going beyond the assigned work and trying to solve new problems in math.

36 Mathematics is enjoyable and stimulating to me.

37 I have never liked mathematics, and it is my most dreaded subject.

38 Mathematics is dull and boring because it leaves no room for personal opinion.

39 I am interested and willing to acquire further knowledge of mathematics.

40 There is nothing creative about mathematics; it is just memorizing formulas and things. 